Jurnal Sporta Saintika

P-ISSN 2502-5651

E-ISSN 2579-5910

\title{
BOLA VOLI: BAGAIMANAKAH KONDISI INDEKS MASSA TUBUH ATLET ?
}

\section{Kusnandar ${ }^{1}$, Didik Rilastiyo Budi ${ }^{2}$, Arfin Deri listiandi ${ }^{3}$, Rifqi Festiawan ${ }^{4}$, Panuwun Joko Nurcahyo ${ }^{5}$, Muhamad Syafei ${ }^{6}$, Ngadiman $^{7}$}

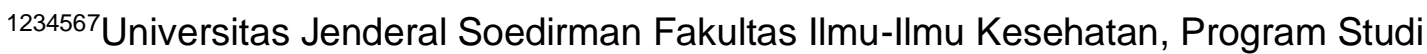 \\ Pendidikan Jasmani, Purwokerto, Indonesia
}

${ }^{1}$ kusnandarunsoed@gmail.com, ${ }^{2}$ didik.rilastiyo.budi@unsoed.ac.id, 3arfinderilistiandi.@unseod.ac.id, ${ }^{4}$ rifai.festiawan@unsoed.ac.id, ${ }^{5}$ panuwunjoko@gmail.com, [6muh.syafeimaulana.unsoed@gmail.com, ${ }^{7}$ ngadiman.unsoed@yahoo.com

\begin{abstract}
Volleyball is a type of Net Game sport that has characteristics of jumping and sliding in various directions quickly. To support performance in volleyball games, an athlete needs to have an ideal Body Mass Index. This study aims to determine the condition of the Body Mass Index in volleyball athletes. The research method used is descriptive ex-postfacto with research samples that are all volleyball athletes at Jenderal Soedirman University with a total of 10 male athletes and 10 female athletes. The research instrument used the Body Mass Index test by measuring the height and weight of the athlete, with a validity and reliability level of 0.98. Data analysis using Benchmark Reference Assessment, then the data is processed using the ms application. Excel. The results showed that the average volleyball athlete at Jenderal Soedirman University had a Body Mass Index in the normal category, but there were 2 male athletes and 2 female athletes with lean BMI, and 2 male athletes and 3 female athletes with overweight BMI. The recommendation of this research is that volleyball athletes from Jenderal Soedirman University must be given proper training, food management and recovery programs so that athletes can have the ideal body weight to support the games.
\end{abstract}

Keywords: Volleyball, Body Mass Index, Athletes

\begin{abstract}
Abstrak
Bola voli merupakan jenis olahraga Net Game yang memiliki karateristik gerakan melompat dan bergeser ke berbagai arah dengan cepat. Untuk mendukung kinerja dalam permainan bola voli, seorang atlet perlu memiliki Indeks Massa Tubuh yang ideal. Penelitian ini bertujuan untuk mengetahui kondisi Indeks Massa Tubuh pada atlet bola voli. Metode penelitian yang digunakan adalah deskriptif ex-postfacto dengan sampel peneliitan yaitu seluruh atlet bola voli Universitas Jenderal Soedirman dengan jumlah 10 atlet putra dan 10 atlet putri. Instrumen penelitian menggunakan tes Indeks Massa Tubuh dengan cara mengukur tinggi dan berat badan atlet, dengan tingkat validitas dan reliabilitas sebesar 0,98. Analisis data menggunakan Penilaian Acuan Patokan (PAP), kemudian data diolah menggunakan aplikasi ms. Excel. Hasil penelitian menunjukan bahwa rata-rata atlet bola voli Universitas Jenderal Soedirman memiliki Indeks Massa Tubuh pada kategori normal, akan tetapi terdapat 2 atlet putra dan 2 atlet putri dengan IMT kurus, serta 2 atlet putra dan 3 atlet putri dengan IMT berat badan lebih. Rekomendasi dari penelitian ini yaitu atlet bola voli Universitas Jenderal Soedirman harus diberikan program latihan, Management Food dan Recovery yang tepat sehingga atlet dapat memiliki berat badan ideal untuk menunjang permainan.
\end{abstract}

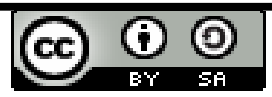


Jurnal Sporta Saintika

P-ISSN 2502-5651

E-ISSN 2579-5910

Kata kunci: Bola Voli, Indeks Massa Tubuh, Atlet.

\section{PENDAHULUAN}

Bola voli merupakan permainan yang memerlukan kerjasama tim dengan saling mendukung satu pemain dengan yang lainnya. Dalam proses permainan atau pertandingan bola voli diperlukan kekompakan, teknik dan keterampilan bermain yang baik dari setiap anggota tim. Agar mencapai performa permainan yang baik pemain bola voli harus meningkatkan faktor kondisi fisik, teknik dasar, teknik bermain dan mental yang kuat untuk bekerjasama dengan anggota tim (Agustan, 2017; Asnaldi, 2020; Faozi et al., 2019; Wijaya et al., 2018). Faktor fisik maupun non fisik merupakan komponen penting yang perlu dikuasai oleh seluruh atlet bola voli.

Faktor lain yang menjadi komponen penting dari permainan bola voli yaitu antropometri yang dimiliki oleh atlet. Antropometri merupakan alat memprediksi penampilan untuk mencapai keberhasilan dalam olahraga prestasi (Brunkhorst \& Kielstein, 2013; Cristian Cosmin et al., 2014; Milić et al., 2017; Popovic et al., 2014). Permainan bola voli didominasi oleh karakteristik gerakan melompat untuk melakukan serangan maupun bertahan (Arjuna, 2020). Pada permainan bola voli seorang atlet harus memukul bola dan melewati net menggunakan berbagai gerakan melompat dengan ketinggian bervariasi sehingga antropometri memiliki peranan yang sangat penting.

Hasil penelitian terdahulu menunjukan bahwa pada kejuaraan internasional selama reli berlangsung rata-rata pemain di garis depan melakukan gerakan lompatan sebanyak 3-4 kali dalam durasi waktu 12 detik (Sheppard et al., 2007). Hasil kajian tersebut memperkuat fakta bahwa faktor antropomerti berupa tinggi dan berat badan menjadi kriteria penting dalam pemilihan dan pembinaan atlet bola voli.

Komposisi antropometri yang ideal dan didukung dengan teknik yang baik akan menghasilkan performa prima seorang atlet bola voli dalam pertandingan. Karakteristik antropometrik, komposisi dan massa tubuh berkontribusi terhadap kinerja latihan dan pertandingan (Akpınar et al., 2012; Massuça \& Fragoso, 2011; Popovic et al., 2014). Antropometri pada cabang olahraga bola voli terkait erat dengan, tingkat Indeks Massa Tubuh (IMT) yang dimiliki oleh atlet karena IMT ideal akan berpengaruh terhadap antropometri ideal.

Indeks Massa Tubuh merupakan hasil perhitungan dari berat badan $(\mathrm{kg})$ di bagi dengan tinggi badan (m) yang dikuadratkan (Arjuna, 2020). Lebih lanjut, Budi et al (2020) menjelaskan Indeks Massa Tubuh (IMT) dapat digunakan untuk mengukur komposisi tubuh 
Jurnal Sporta Saintika

P-ISSN 2502-5651

E-ISSN 2579-5910

dan kategorisasi berat badan atlet pada level kurus, normal atau overweight. Indeks Massa Tubuh ideal merupakan modal penting dalam menunjang keterampilan teknik serta kemampuan fisik seorang atlet bola voli.

Kajian lebih lanjut terhadap atlet bola voli menunjukan bahwa komposisi tubuh pada atlet bola voli berpengaruh pada saat melakukan teknik melompat dan melakukan berbagai teknik dalam permainan (Acar \& Eler, 2019; Moncef et al., 2012). Pengukuran komposisi tubuh telah menjadi bagian penting dalam program identifikasi bakat dan pemilihan atlet bola voli yang menyebabkan tim bola voli lebih kompetitif pada tingkat nasional maupun internasional (DeCaro, 2018; Valleser et al., 2018). Oleh sebab itu pengukuran Indeks Massa Tubuh memiliki peranan penting sebagai salah satu parameter dalam pemilihan dan pembinaan atlet bola voli.

Pengukuran Indeks Massa Tubuh telah menjadi prioritas penting di olahraga bola voli, akan tetapi di Indonesia khususnya pada atlet di perguruan tinggi, pengukuran Indeks Massa Tubuh yang dimiliki oleh atlet mahasiswa belum banyak diterapkan. Sejauh ini proses pembinaan atlet lebih menitik beratkan kepada aspek fisik, teknik, taktik dan mental. Sedangkan pada aspek kesehatan dalam hal ini pengukuran Indeks Massa Tubuh masih dianggap faktor yang kurang penting.

Pembinaan prestasi pada olahraga bola voli di tingkat perguruan tinggi merupakan proses pembinaan lanjutan dari jenjang sebelumnya, dan memiliki tingkat persaingan yang lebih kompetitif. Akan tetapi pada tingkat perguruan tinggi, kondisi tubuh atlet dimungkinkan telah mengalami kelebihan berat badan maupun obesitas karena faktor usia. Hasil penelitian terdahulu menunjukan bahwa atlet bola voli senior Indonesia memiliki tingkat IMT dalam kategori kelebihan berat badan(Wibowo \& Hakim, 2019). Berdasarkan hasil kajian penelitian mengenai keterkaitan IMT dan performa prestasi olahraga maka pengukuran Indeks Massa Tubuh pada atlet bola voli pada perguruan tinggi krusial untuk dilakukan sebagai langkah awal pembinaan atlet.Pembinaan prestasi bertujuan untuk mempersiapkan atlet pada perguruan tinggi untuk bersaing di level daerah maupun nasional dengan memngikuti beberapa multi event seperti POM Rayon, POMPROV maupun POMNAS.

Penelitian ini bertujuan untuk menganalisis tingkat Indeks Massa Tubuh (IMT) yang dimiliki oleh atlet bola voli Universitas Jenderal Soedirman untuk memberikan gambaran kategorisasi berat badan atlet bola voli. Hasil pengukuran IMT merupakan dasar acuan bagi program pelatihan dan pembinaan atlet yang tepat. 
Jurnal Sporta Saintika

P-ISSN 2502-5651

E-ISSN 2579-5910

\section{METODELOGI PENELITIAN}

Metode yang digunakan dalam penelitian ini adalah deskriptif ex-postfacto. Expostfacto merupakan jenis metode penelitian yang tidak memiliki kontrol langsung terhadap variabel (Sugiyono, 2016). Populasi dan Sampel menggunakan seluruh atlet bola voli Universitas Jenderal Soedirman dengan jumlah 20 orang atlet. Teknik penentuan sampel yang digunakan yaitu total sampling. Instrumen penelitian yang digunakan yaitu tes Indeks Massa tubuh (IMT) dengan rumus penghitungan IMT yang dilakukan dengan mengukur data berat badan (kg) dibagi tinggi badan (m2) (Nurhasan \& Narlan, 2011).

$$
\mathrm{IMT}=\frac{\mathrm{BB}(\mathrm{kg})}{\mathrm{TB}(\mathrm{m}) \times \mathrm{TB}(\mathrm{m})}
$$

Gambar 1. Rumus IMT

Teknik pengumpulan data dilakukan menggunakan prosedur tes pengukuran berat dan tinggi badan mengadopsi dari Nurhasan dan Narlan (2011) dengan tingkat validitas dan reliabilitas sebesar 0,98. Analisis data menggunakan Penilaian Acuan Patokan (PAP) untuk mengukur kriteria Indeks Massa Tubuh (IMT) untuk anak usia 5-20 berdasarkan data dari (Kemenkes, 2013) sebagaimana yang tertera pada Tabel 1 dibawah ini.

Tabel 1. Kriteria Indeks Massa Tubuh (IMT)

\begin{tabular}{|l|l|l|}
\hline No. & Kriteria & IMT $\left(\mathbf{k g} / \mathbf{m}^{2}\right)$ \\
\hline 1 & Kurus & IMT $<18,5$ \\
\hline 2 & Normal & IMT $18,5-25,89$ \\
\hline 3 & Berat Badan Lebih & IMT 25,90 $-26,99$ \\
\hline 4 & Obesitas & IMT 27 ke atas \\
\hline
\end{tabular}

Data hasil pengukuran Indeks Massa Tubuh kemudian dianalisis dengan menggunakan aplikasi Microsoft Excel sehingga dapat diketahui jumlah atlet bola voli yang termasuk dalam kategori IMT Kurus, Normal, Berat Badan Lebih (Overwight) maupun Obesitas.

\section{HASIL PENELITIAN}

Hasil penelitian tingkat Indeks Massa Tubuh (IMT) pada atlet bola voli Universitas Jenderal Soedirman Purwokerto dengan menggunakan Penilaian Acuan Patokan (PAP) dapat dilihat pada Tabel 2 dan Gambar 2 di bawah ini. 
Jurnal Sporta Saintika

P-ISSN 2502-5651

E-ISSN 2579-5910

Tabel 2. Indeks Massa Tubuh Atlet Bola Voli Putra dan Putri

\begin{tabular}{|l|l|l|}
\hline No. & Kriteria IMT & Jumlah \\
\hline 1 & Kurus & 4 \\
\hline 2 & Normal & 11 \\
\hline 3 & Berat Badan Lebih & 5 \\
\hline 4 & Obesitas & 0 \\
\hline
\end{tabular}

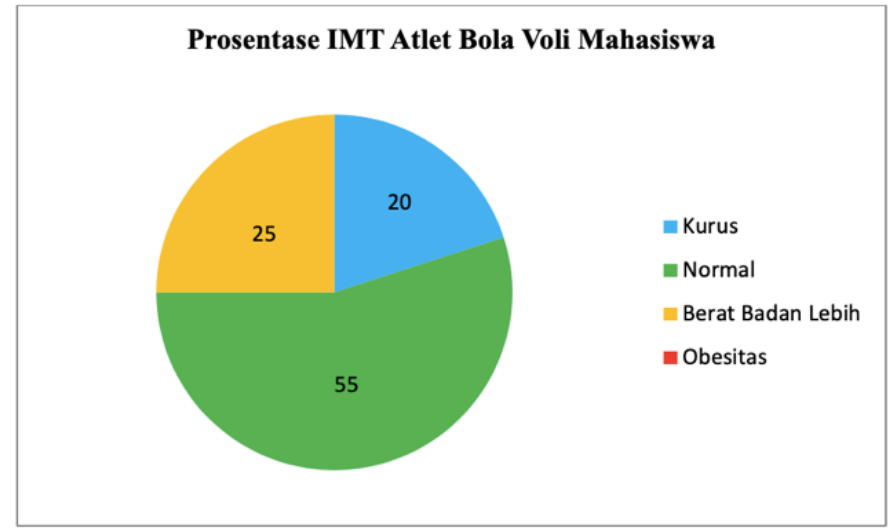

Gambar 2. Diagram Kriteria IMT Atlet Bola Voli

Berdasarkan tabel 2 dan gambar 2 diatas menunjukan bahwa Indeks Massa Tubuh (IMT) yang dimiliki oleh atlet bola voli Universitas Jenderal Soedirman menunjukan 4 atlet atau 20\% berada pada kategori Kurus, 11 atlet atau 55\% berada pada kategori normal, 5 atlet atau $25 \%$ berada pada kategori berat badan lebih dan tidak ada atlet yang memiliki IMT kategori obesitas. Dengan demikian rata-rata Indek Massa Tubuh (IMT) pada atlet bola voli Universitas Jenderal Soedirman berada dalam kategori normal.

Berdasakan jenis kelamin terdapat perbedaan antara rata-rata Indeks Massa Tubuh pada atlet bola voli putra dan putri. Data Indeks Massa Tubuh (IMT) pada atlet bola voli putra Universitas Jenderal Soedirman berdasarkan Penilaian Acuan Patokan (PAP) dapat di lihat pada tabel 3 dan gambar 3 di bawah ini.

Tabel 3. Indeks Massa Tubuh Atlet Bola Voli Putra

\begin{tabular}{|l|l|l|}
\hline No. & Kriteria IMT & Jumlah \\
\hline 1 & Kurus & 2 \\
\hline 2 & Normal & 6 \\
\hline
\end{tabular}


Jurnal Sporta Saintika

P-ISSN 2502-5651

E-ISSN 2579-5910

\begin{tabular}{|l|l|l|}
\hline 3 & Berat Badan Lebih & 2 \\
\hline 4 & Obesitas & 0 \\
\hline
\end{tabular}

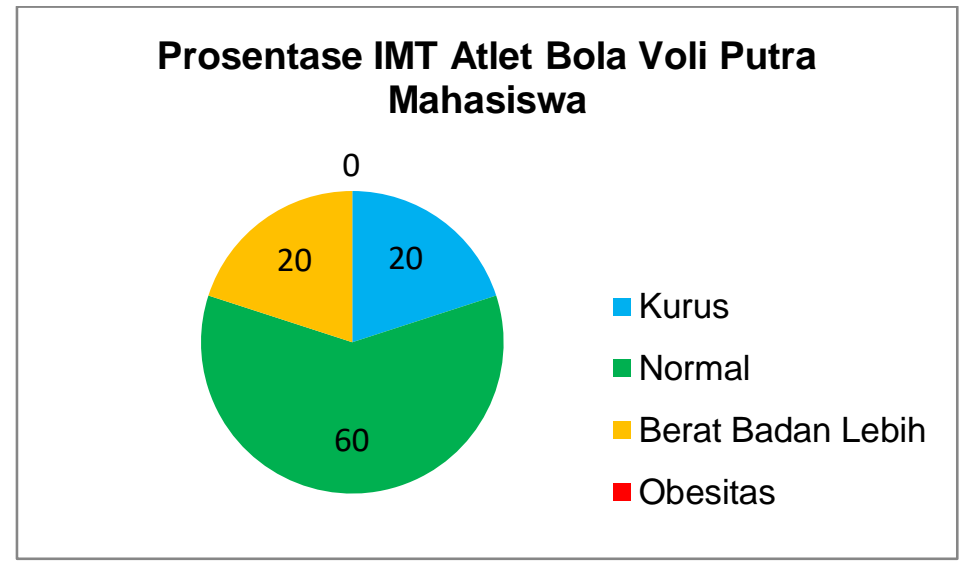

Gambar 3. Diagram Kriteria IMT Atlet Bola Voli Putra

Berdasarkan tabel 3 dan gambar 3 diatas menunjukan bahwa Indeks Massa Tubuh (IMT) atlet bola voli putra menunjukan 2 atlet atau sebesar $40 \%$ berada pada kategori Kurus, 6 atlet atau sebesar $60 \%$ berada pada kategori normal, 2 atlet atau sebesar $20 \%$ berada pada kategori berat badan lebih, serta tidak ada atlet putra yang memiliki IMT kategori obesitas. Rata-rata Indeks Massa Tubuh (IMT) pada atlet bola voli putra Universitas Jenderal Soedirman memiliki rata-rata IMT dengan kategori Normal. Data Indeks Massa Tubuh (IMT) pada atlet bola voli putri dapat di lihat pada tabel 4 dan gambar 4 di bawah ini.

Tabel 4. Indeks Massa Tubuh Atlet Bola Voli Putri

\begin{tabular}{|l|l|l|}
\hline No. & Kriteria IMT & Jumlah \\
\hline 1 & Kurus & 2 \\
\hline 2 & Normal & 5 \\
\hline 3 & Berat Badan Lebih & 3 \\
\hline 4 & Obesitas & 0 \\
\hline
\end{tabular}


Jurnal Sporta Saintika

P-ISSN 2502-5651

E-ISSN 2579-5910

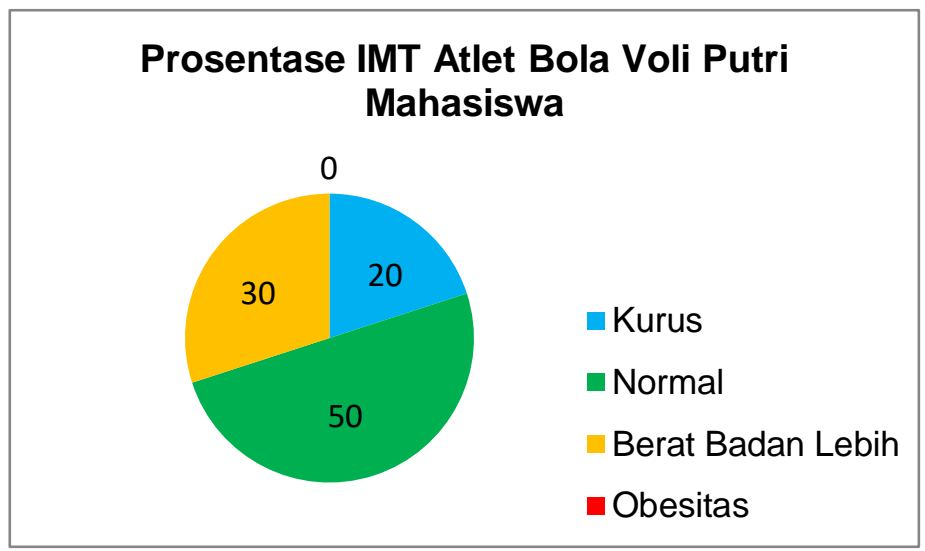

Gambar 4. Diagram Kriteria IMT Atlet Bola Voli Putri

Data pada tabel 4 dan gambar 4 di atas menunjukan Indeks Massa Tubuh (IMT) yang dimiliki oleh atlet bola voli putri dengan jumlah 2 atlet atau $20 \%$ berada pada kategori Kurus, 5 atlet atau $50 \%$ berada pada kategori normal, 3 atlet atau $30 \%$ berada pada kategori kelebihan berat badan, serta tidak ada atlet yang memiliki IMT kategori obesitas. Hal ini menunjuka bahwa rata-rata Indek Massa Tubuh (IMT) pada atlet bola voli putri Universitas Jenderal Soedirman berada pada kategori normal.

\section{PEMBAHASAN}

Indeks Massa Tubuh pada atlet bola voli Universitas Jenderal Soedirman secara keseluruhan berada pada kategori normal, hal ini menunjukan hasil yang baik karena permainan bola voli membutuhkan komposisi tubuh yang ideal untuk dapat melakukan keterampilan dalam permaian. Bola voli adalah olahraga yang menonjolkan karakteristik tubuh yang ideal selain kemampuan fisik dan teknik (Carvajal et al., 2012; Palao et al., 2014). Lebih lanjut hasil penelitian terdahulu menunjukan bahwa kemampuan melompat atlet bola voli dalam melakukan smash dan block dipengaruhi oleh berat badan dan Indeks Massa Tubuh atlet (Acar \& Eler, 2019; Bialoskórska et al., 2016). Oleh karena itu, atlet bola voli perlu memperhatikan komposisi tubuh yang dimiliki.

Hasil penelitian juga menunjukan bahwa terdapat atlet bola voli putra dan putri yang berada pada tingkat Indeks Massa Tubuh dalam kategori kurus dan kelebihan berat badan. Kondisi tersebut jelas kurang menguntungkan bagi atlet secara individu dan juga tim, karena dengan berat badan yang kurang ideal maka dapat mengurangi efektivitas atlet dalam melakukan berbagai teknik permanian bola voli. Teknik permainan bola voli dapat dilakukan dengan lebih berhasil apabila memiliki kondisi fisik dan antropomerti (tinggi dan berat badan) yang baik (Milić et al., 2017). Hasil penelitan menunjukan bahwa komposisi tubuh seorang 
Jurnal Sporta Saintika

P-ISSN 2502-5651

E-ISSN 2579-5910

atlet bola voli memiliki dampak penting dalam melakukan kinerja latihan dan pertandingan (Hyatt \& Kavazis, 2019). Berdasarkan hasil tersebut maka perlu disesuaikan Indeks Massa Tubuh atlet tersebut.

Komposisi Indeks Massa Tubuh atlet bola voli putri Universitas Jenderal Soedirman menunjukan tingkat kelebihan berat badan dengan jumlah yang lebih banyak dibandingnkan dengan atlet bola voli putra. Hasil ini menunjukan bahwa atlet bola voli putri pada jenjang perguruan tinggi memiliki kecenderungan mengalami kelebihan berat badan. Prevalnesi kelebihan berat badan pada atlet bola voli putri memiliki tingkat yang cukup tinggi (Nikolaidis, 2013; Widanita et al., 2019). Hasil penelitian terdahulu juga menunjukan bahwa atlet bola voli putra memiliki efektifitas yang lebih baik dibandingkan dengan atlet putri dalam hal melakukan keterampilan bola voli karena memiliki komposisi tubuh yang lebih ideal (Nikos et al., 2010).

Berat badan berlebih pada atlet memicu efek negatif lain berupa tingginya risiko terjadinya cidera. Tingginya kasus cidera olahraga dipengaruhi oleh tingkat aktivitas fisik, jenis kelamin, antropometri dan komposisi tubuh (Vanderlei et al., 2013). Komposisi tubuh berupa Indeks Massa Tubuh penting diperhatikan agar mengurangi risiko terjadinya cidera pada atlet karena karakteristik pemainan bola voli yang didominasi dengan gerakan melompat.

Atlet bola voli yang mengalami kelebihan berat badan dipengaruhi oleh berbagai faktor, baik karena dari program latihan maupun tuntutan prestasi akademik. Atlet yang berada dilingkungan perguruan tinggi harus membagi konsentrasi antara pendidikan dan latihan, sehingga membuat atlet memiliki beban lebih dan dapat mempengaruhi performa atlet (Hyatt \& Kavazis, 2019; Listiandi et al., 2020).

Atlet bola voli dengan karakterisik badan kurus, memiliki sedikit risiko baik cidera maupun penurunan performa dalam pertandingan maupun latihan dibandingkan dengan atlet yang memiliki kelebihan berat badan. Hasil penelitian menunjukan bahwa penampilan tim bola voli putri dengan komposisi tubuh kurus menunjukan performa yang lebih baik dibandingkan dengan atlet dengan berat badan lebih, terutama pada saat melakukan teknik smash dan Block (DeCaro, 2018). Atlet dengan komposisi tubuh kurus memiliki kecenderungan dapat bergerak lebih lincah dibandingkan dengan atlet dengan komposisi berat badan berlebih, sehingga memudahkan pada saat melakukan berbagai keterampilan dalam permainan bola voli (Acar \& Eler, 2019).

Berdasarkan analisis kondisi Indeks Massa Tubuh pada atlet bola voli pada Universitas Jenderal Soedirman maka rekomendasi yang dapat diberikan adalah dengan 
Jurnal Sporta Saintika

P-ISSN 2502-5651

E-ISSN 2579-5910

melakukan pengaturan program latihan yang menyesuaikan kondisi Indeks Massa Tubuh masing-masing atlet.

Program latihan yang tepat, pengaturan asupan gizi dan pola istirahat yang baik dapat mengurangi risiko terjadinya berat badan berlebih pada atlet bola voli, sehingga dapat memiliki komposisi tubuh yang ideal untuk mendukung penampilan atlet dalam latihan maupun pertandingan. Dengan diketahuinya Indeks Massa Tubuh, maka pelatih dapat memberikan program yang sesuai dan atlet juga memiliki motivasi untuk mencapai komposisi tubuh yang ideal.

\section{KESIMPULAN}

Rata-rata Indeks Massa Tubuh (IMT) yang dimiliki oleh atlet bola voli Universitas Jenderal Soedirman berada pada kategori normal. Terdapat $20 \%$ dari atlet bola voli putra dan $30 \%$ dari atlet bola voli putri yang berada pada kategori IMT Kelebihan berat badan. Selain itu, hasil penelitian juga menunjukan bahwa tedapat $20 \%$ atlet putra dan putri berada pada kategori berat badan kurus. Diperlukan strategi pengaturan pola makan dan program latihan kepada atlet dengan IMT kelebihan berat badan sehingga dapat memiliki Indeks Massa Tubuh (IMT) dalam kategori normal. IMT ideal pada atlet bola voli diharapkan dapat menunjang peningkatan keterampilan bermain bola voli yang dapat mendukung tercapainya peningkatan prestasi olahraga bola voli.

Saran bagi penelitian selanjutnya dapat mengkaji mengenai Indeks Massa Tubuh (IMT) paada pada atlet bola voli di jenjang pendidikan yang berbeda atau di klub bola voli profesional. Penelitian lanjutan dapat berupa identifikasi program latihan, asupan gizi dan tingkat recovery yang dilakukan oleh atlet yang dikaitkan dengan kondisi IMT atlet tersebut.

\section{DAFTAR PUSTAKA}

Acar, H., \& Eler, N. (2019). The Relationship between Body Composition and Jumping Performance of Volleyball Players. Journal of Education and Training Studies, 7(3), 192. https://doi.org/10.11114/jets.v7i3.4047

Agustan, B. (2017). Perbandingan Latihan Kotak Berwarna Dengan Segi Tiga Angka Terhadap Passing Atas Bola Voli. JUARA: Jurnal Olahraga, 2(2), 121. https://doi.org/10.33222/juara.v2i2.51

Akpınar, S., Zileli, R., Senyüzlü, E., \& Tunca, S. (2012). Predictors Affecting the Ranking in Women Armwrestling Competition. J. Sports Sci. Med, 1(1), 11-14.

Arjuna, F. (2020). Pengaruh Latihan Sirkuit Dengan Interval Istirahat Tetap dan Menurun Terhadap Komposisi Tubuh Pemain Bola Voli Putri. MEDIKORA, 19(1), 8-16. https://doi.org/10.21831/MEDIKORA.V19l1.30975 
Jurnal Sporta Saintika

P-ISSN 2502-5651

E-ISSN 2579-5910

Asnaldi, A. (2020). Hubungan Kelentukan dan Daya Ledak Otot Lengan Terhadap Ketepatan Smash Bolavoli. Physical Activity Journal (PAJU), $1(2), \quad$ 160-175. doi:10.20884/1.paju.2020.1.2.2556

Bialoskórska, M., Tomczyk, E., Tomczyk, A., \& Szafraniec, R. (2016). Relations Between Vertical Jump Height and Volleyball Players' Body Composition. Scientific Review of Physical Culture, 6(October), 56-62. http://62.93.45.40/srpc/Articles/Volume-6/lssue1/6.aspx

Brunkhorst, L., \& Kielstein, H. (2013). Comparison of anthropometric characteristics between professional triathletes and cyclists. Biology of Sport, 30(4), 269-273. https://doi.org/10.5604/20831862.1077552

Budi, D. R., Listiandi, A. D., Festiawan, R., Widanita, N., \& Anggraeni, D. (2020). Indeks Masa Tubuh (IMT): Kajian Analisis pada Atlet Renang Junior Usia Sekolah Dasar. TEGAR: Journal of Teaching Physical Education in Elementary School, 3(2), 46-53. https://doi.org/10.17509/tegar.v3i2.24452

Carvajal, W., Betancourt, H., Leoń, S., Deturnel, Y., Martińez, M., Echevarriá, I., Castillo, M. E., \& Serviat, N. (2012). Kinanthropometric profile of cuban women olympic volleyball champions. MEDICC Review, 14(2), 16-22. https://doi.org/10.1590/S155579602012000200006

Cristian Cosmin, S., Alexandra Mihaela, R., \& Claudiu, A. (2014). Anthropometric characteristics, body composition and physical performance of female cadet volleyball players. Journal of Physical Education and Sport \& (JPES), 16(1), 664-667. https://doi.org/10.7752/jpes.2016.s1106

DeCaro, E. (2018). Body Composition vs Athletic Performance in Volleyball. Williams Honors College, Honors Research

https://ideaexchange.uakron.edu/honors_research_projects/747

Faozi, F., Sanusi, H., \& Listiandi, A. (2019). Pengaruh Model Pembelajaran Kooperatif Tipe STAD Terhadap Keterampilan Passing Bawah Dalam Permainan Bola Voli Di SMA Islam Al-Fardiyatussa'adah Citepus Palabuhanratu. Physical Activity Journal (PAJU), 1(1), 51-60. doi:10.20884/1.paju.2019.1.1.2001

Hyatt, H. W., \& Kavazis, A. N. (2019). Body Composition and Perceived Stress through a Calendar Year in NCAA I Female Volleyball Players. International Journal of Exercise Science, 12(5), 433-443. http://www.ncbi.nlm.nih.gov/pubmed/30899353

Kemenkes. (2013). Pedoman gizi olahraga prestasi. Bina Gizi dan KIA.

Listiandi, A. D., Budi, D. R., Festiawan, R., Nugraha, R., faozi, faiz, \& Bakhri, R. S. (2020). Hubungan Body Fat Dan Physique Rating Dengan Cardiorespiratory Fitness Mahasiswa. Jurnal MensSana, 5(1), 78-86. https://doi.org/10.24036/jm.v5i1.144

Massuça, L., \& Fragoso, I. (2011). Study of Portuguese handball players of different playing status. A morphological and biosocial perspective. Biology of Sport, 28(1), 37-44. 
Jurnal Sporta Saintika

P-ISSN 2502-5651

E-ISSN 2579-5910

Milić, M., Grgantov, Z., Chamari, K., Ardigò, L. P., Bianco, A., \& Padulo, J. (2017). Anthropometric and physical characteristics allow differentiation of young female volleyball players according to playing position and level of expertise. Biology of Sport, 34(1), 19-26. https://doi.org/10.5114/biolsport.2017.63382

Moncef, C., Said, M., Olfa, N., \& Dagbaji, G. (2012). Influence of morphological characteristics on physical and physiological performances of Tunisian elite male handball players. Asian Journal of Sports Medicine, 3(2), 74-80. https://doi.org/10.5812/asjsm.34700

Nikolaidis, P. T. (2013). Body mass index and body fat percentage are associated with decreased physical fitness in adolescent and adult female volleyball players. Journal of Research in Medical Sciences, 18(1), 22-26.

Nikos, B., Karolina, B., \& Grigoris, M. (2010). Performance effectiveness in Complex II of Olympic-level male and female volleyball players. International Journal of Volleyball Research, 10(1), 26-32.

Nurhasan, \& Narlan, A. (2011). Tes dan Pengukuran Pendidikan Olahraga. Pendidikan Jasmani Kesehatan dan Rekreasi, Universitas Siliwangi.

Palao, J. M., Manzanares, P., \& Valadés, D. (2014). Anthropometric, physical, and age differences by the player position and the performance level in volleyball. Journal of Human Kinetics, 44(1), 223-236. https://doi.org/10.2478/hukin-2014-0128

Popovic, S., Bjelica, D., Jaksic, D., \& Hadzic, R. (2014). Comparative study of anthropometric measurement and body composition between elite soccer and volleyball players. International Journal of Morphology, 32(1), 267-274. https://doi.org/10.4067/S0717-95022014000100044

Sheppard, J., Newton, R., \& McGuigan, M. (2007). The Effect of Accentuated Eccentric Load on Jump Kinetics in High-Performance Volleyball Players. International Journal of Sports Science \& Coaching, 2(3), 267-273. https://doi.org/10.1260/174795407782233209

Sugiyono. (2016). Metode Penelitian Kualitatif, Kuantitatif, dan R and D. Alfabeta.

Valleser, C. W. M., Bersola, K. A. R., Mallari, M. F. T., Papa, E. L. V., Diaz, F. C. B., Maghanoy, M. L. A., \& Lariosa, C. J. D. (2018). Anthropometric profile of elite women's volleyball players in the Philippines. Turkish Journal of Kinesiology, 4(2), 53-57. https://doi.org/10.31459/turkjkin.417481

Vanderlei, F. M., Bastos, F. N., Tsutsumi, G. Y. C., Vanderlei, L. C. M., Netto, J., \& Pastre, C. M. (2013). Characteristics and contributing factors related to sports injuries in young volleyball players. BMC Research Notes, 6(1), 415. https://doi.org/10.1186/1756-0500-6415

Wibowo, E. T., \& Hakim, A. A. (2019). Profil Indeks Massa Tubuh Pada Atlet Tim Nasional Indonesia Pada Asian Games 2018 Eko. Jurnal Kesehatan Olahraga, 8(1), 131-140. file://C:/Users/User/Downloads/fvm939e.pdf 
Jurnal Sporta Saintika

P-ISSN 2502-5651

E-ISSN 2579-5910

Widanita, N., Nanang Kusuma, M. H., Budi, D., Suhartoyo, T., Deri Listiandi, A., \& Gitya, N. (2019). The effectiveness of pilates training model towards BMI and muscle mass for overweight women. Ann Trop \& Public Health, 11. https://doi.org/10.36295/ASRO.2019.22115

Wijaya, E. S., Rahayu, T., \& Sugiharto, S. (2018). View of Evaluation Program of Female's Volleyball Achivement on Junior High School of Bantarkawung sub-district. Journal of Physical Education and Sports, 7(1), 36-42. https://journal.unnes.ac.id/sju/index.php/jpes/article/view/21517/10767 